\title{
Construction of College Teachers' emotional labor strategy model based on emotional intelligence theory
}

\author{
Hang Lanlv ${ }^{1, *}$, Chen Ming-Tsung ${ }^{2}$ \\ ${ }^{1}$ School of Economics \& Management, Nanjing Tech University, Nanjing, Jiangsu 211816, China. \\ ${ }^{2}$ School of Public Administration, Nanfang College of Sun Yat-sen University, Guangzhou, Guangdong, 510000, China
}

\begin{abstract}
In China, colleges and universities bear the important responsibility of cultivating high-quality talents. The quality, ability and work performance of university teachers are more and more concerned by the whole society, including colleges and universities. Emotional labor of college teachers refers to the process in which teachers control and express their emotions according to the requirements of the school. Emotional intelligence is related to emotional labor, and emotional labor strategy is the means to optimize the emotional labor process. College Teachers' emotional labor strategies include five basic strategies: self-awareness, selfregulation, self motivation, empathy, and social skills. It can stimulate college teachers' real emotions and deep acting behaviors, help to avoid job burnout and enhance their sense of professional identity and happiness. From the perspective of emotional labor, it is of great significance to study the working state of young teachers and put forward the strategies to improve their working enthusiasm, whether it is of great significance to the career development of young teachers, the improvement of teaching and scientific research quality and the cultivation of talents.
\end{abstract}

\section{THEORETICAL ANALYSIS FRAMEWORK OF EMOTIONAL INTELLIGENCE THEORY AND EMOTIONAL LABOR}

\subsection{The connotation and content division of emotional intelligence theory}

Emotional intelligence is the ability of people to perceive their own and others' emotions or emotions, and construct their thinking and action based on it. Emotional intelligence can be generally summarized into three dimensions: emotional expression, emotional regulation and emotional problem solving. Emotional expression can be divided into two types: verbal expression and nonverbal expression. Emotional regulation includes regulating one's own and other's emotions, and emotional problem solving can be summarized into three dimensions It involves planning, creative thinking and shifting attention. Although emotional intelligence theory focuses on emotion, it also includes the expression, regulation and application of emotion. Since the theory of emotion was put forward, it has attracted the attention of many scholars. The related research not only includes the category of pedagogy, but also includes the category of psychology and management. From this, some representative schools and emotional intelligence models have emerged, such as constructing the corresponding theoretical model of emotional intelligence from the perspective of ability orientation, mixed orientation, Personality Orientation and competency.

Table1. arrangement of several theoretical models of emotional intelligence

\begin{tabular}{|c|c|l|}
\hline $\begin{array}{c}\text { theoretical } \\
\text { model }\end{array}$ & representative figure & \multicolumn{1}{c|}{ Research contents and viewpoints } \\
\hline $\begin{array}{c}\text { Model of } \\
\text { emotional } \\
\text { intelligence } \\
\text { ability }\end{array}$ & $\begin{array}{c}\text { Salovey, Mayer, } \\
\text { Garuso, Roberts, } \\
\text { Barsade }\end{array}$ & $\begin{array}{l}\text { Scholars have defined the concept of emotional intelligence and } \\
\text { gradually refined the connotation scope of emotional intelligence; } \\
\text { Salovey and Mayer (1997) divided the emotional intelligence model into } \\
\text { three dimensions: evaluation and expression of emotion, management of } \\
\text { emotion and application of emotion, Garuso (2000) summarized the } \\
\text { emotional intelligence model into four dimensions: emotion perception } \\
\text { and expression, emotion integrated thinking, understanding and } \\
\text { analyzing emotion, and reflective emotion management. }\end{array}$ \\
\hline $\begin{array}{c}\text { Emotional } \\
\text { intelligence }\end{array}$ & $\begin{array}{c}\text { Oetrides, Furnham, } \\
\text { Thorndike, Gardner, }\end{array}$ & $\begin{array}{l}\text { Based on alexithymia, emotional communication and empathy, the } \\
\text { concept of emotional intelligence is proposed. The theoretical model }\end{array}$ \\
\hline
\end{tabular}

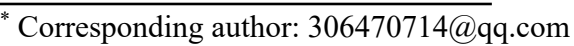

(c) The Authors, published by EDP Sciences. This is an open access article distributed under the terms of the Creative Commons Attribution License 4.0 


\begin{tabular}{|c|c|l|}
\hline trait model & Petrides, Furnham & $\begin{array}{l}\text { includes 15 common aspects and four basic dimensions: emotional, } \\
\text { social, self-control and well-being. }\end{array}$ \\
\hline $\begin{array}{c}\text { Mixed } \\
\text { model of } \\
\text { emotional } \\
\text { intelligence }\end{array}$ & Bar-on & $\begin{array}{l}\text { The concept of "emotional social governance" is replaced by "emotional } \\
\text { intelligence", and it is proposed that emotional intelligence affects the } \\
\text { individual's needs for understanding others and self-expression. } \\
\text { Emotional intelligence theory is divided into individual dimension, } \\
\text { interpersonal dimension, stress management dimension, adaptability } \\
\text { dimension and general mood dimension. }\end{array}$ \\
\hline $\begin{array}{c}\text { Competency } \\
\text { model of } \\
\text { emotional } \\
\text { intelligence }\end{array}$ & Goleman, Boyatzis & $\begin{array}{l}\text { Emotional intelligence refers to the ability to control emotional impulses, } \\
\text { interpret other people's emotions and deal with various relationships. } \\
\text { According to this concept, emotional intelligence is constructed into five } \\
\text { dimensions: self-awareness, self-regulation, self motivation, empathy } \\
\text { and social skills, and it is subdivided into 25 competency characteristics. }\end{array}$ \\
\hline
\end{tabular}

The above theoretical models mainly focus on the concept and content of emotional intelligence. The analysis angle is different, and the specific definition and analysis dimension are also different. The ability model thinks that emotional intelligence is a kind of non cognitive ability, while the trait model thinks that emotional intelligence is the unity of ability and personality, including all aspects except IQ. In view of the differences among different schools in the theory of emotional intelligence, we should integrate the existing theories in the study of this problem. In fact, some scholars have made a preliminary attempt. Combined with the relevant literature, there are three main ideas: first, to classify and integrate the existing theoretical models of emotional intelligence. Such as distinguishing the concept of emotional competence and emotional intelligence. Secondly, the content of emotional intelligence should be further clarified from the perspective of efficiency criteria, so as to improve the explanatory ability and predictive validity of emotional intelligence on the premise of ensuring the structural integrity of emotional intelligence. Thirdly, the structural system of emotional intelligence is determined by content analysis and factor analysis, and the model of emotional intelligence is constructed. In addition to the above assumptions, this paper points out that the construction of the theoretical model of emotional intelligence should follow three basic steps: first, determine the content of emotional intelligence from the criterion of effectiveness with the help of content analysis method; secondly, further screen the content of emotional intelligence to establish the structure system of emotional intelligence; finally, factor analysis method is used to analyze the results The system was validated and the influence of different variables, such as country, region, culture, age and so on, was fully considered. After repeated tests and improvements, a reasonable theoretical model of emotional intelligence was established ${ }^{[1]}$.

\subsection{The connotation, characteristics and measurement of emotional labor}

Emotional labor refers to the process in which employees express their emotions on the basis of certain expression rules in order to achieve certain organizational goals. Emotional labor is a dynamic process, including emotional regulation of individual content and external performance. In the dimension division of emotional labor, different scholars have different views, but on the whole, they basically cover two dimensions: deep acting and surface acting. The reason why it is called "acting" is that individuals need to pay a lot of energy to manage their own emotions. Therefore, emotional labor is also a process of "acting". Among them, surface acting mainly refers to the individual camouflages the emotion he wants to express, and the deep acting refers to a way of emotional labor formed by individuals' identification with the organization and their own roles. In addition, some scholars have supplemented the above two dimensions, adding the dimension of real emotion.

There are three obvious characteristics of College Teachers: firstly, emotional labor occurs in the interaction between teachers and students, including face-to-face communication and voice communication between teachers and students; secondly, teachers' emotional expression will affect students' attitude and behavior; thirdly, teachers' emotional expression needs to follow certain principles to meet the requirements of students' training objectives It is also necessary to meet the requirements of school management objectives. Specifically, as emotional workers, teachers should be able to treat students with love and patience, and be "student-centered"; at the work level, they should have full enthusiasm for knowledge and desire for continuous learning, and avoid negative emotions in their work.

The selection of measurement tools of emotional labor should be in line with the reality. The initial measurement is single-dimensional. With the deepening of the research, the structure of emotional labor is more detailed, so there are two-dimensional or multidimensional measurement methods. In the measurement of College Teachers' emotional labor, the dimension emotional labor scale is used to measure the frequency, intensity, rule diversity, surface behavior and deep-seated behavior of emotional labor ${ }^{[2]}$. There are also some local adaptations of the teacher emotional labor scale. The scale includes 19 variables from four dimensions: superficial disguise, deep behavior, autonomous emotion regulation and emotional deviation. The scale has good reliability and validity ${ }^{[3]}$. 


\section{CONSTRUCTION OF COLLEGE TEACHERS' EMOTIONAL LABOR MODEL BASED ON EMOTIONAL INTELLIGECE THEORY}

In recent years, with the gradual deepening of higher education reform, college teachers are facing the pressure of teaching, scientific research and other aspects, and need to spend a lot of energy in their work. For university teachers, "teaching and educating people" is still a very difficult task, and this process is at the cost of teachers' emotional work. In contrast, individuals with higher emotional intelligence tend to adopt deep acting strategy or autonomous emotion regulation strategy in emotional labor. However, individuals with low emotional intelligence can not manage their emotions well in the face of greater pressure, and the probability of using surface acting strategy is higher.

\subsection{Two dimensional model of emotional intelligence and emotional labor of College Teachers}

Emotional intelligence is divided into two dimensions: high emotional intelligence and low emotional intelligence. Emotional labor is divided into two dimensions: surface emotional labor and deep emotional labor. Through the correlation between emotional intelligence and emotional labor, a college teacher's emotional labor model under the influence of two factors is constructed. The model can be divided into three levels (Figure 1).

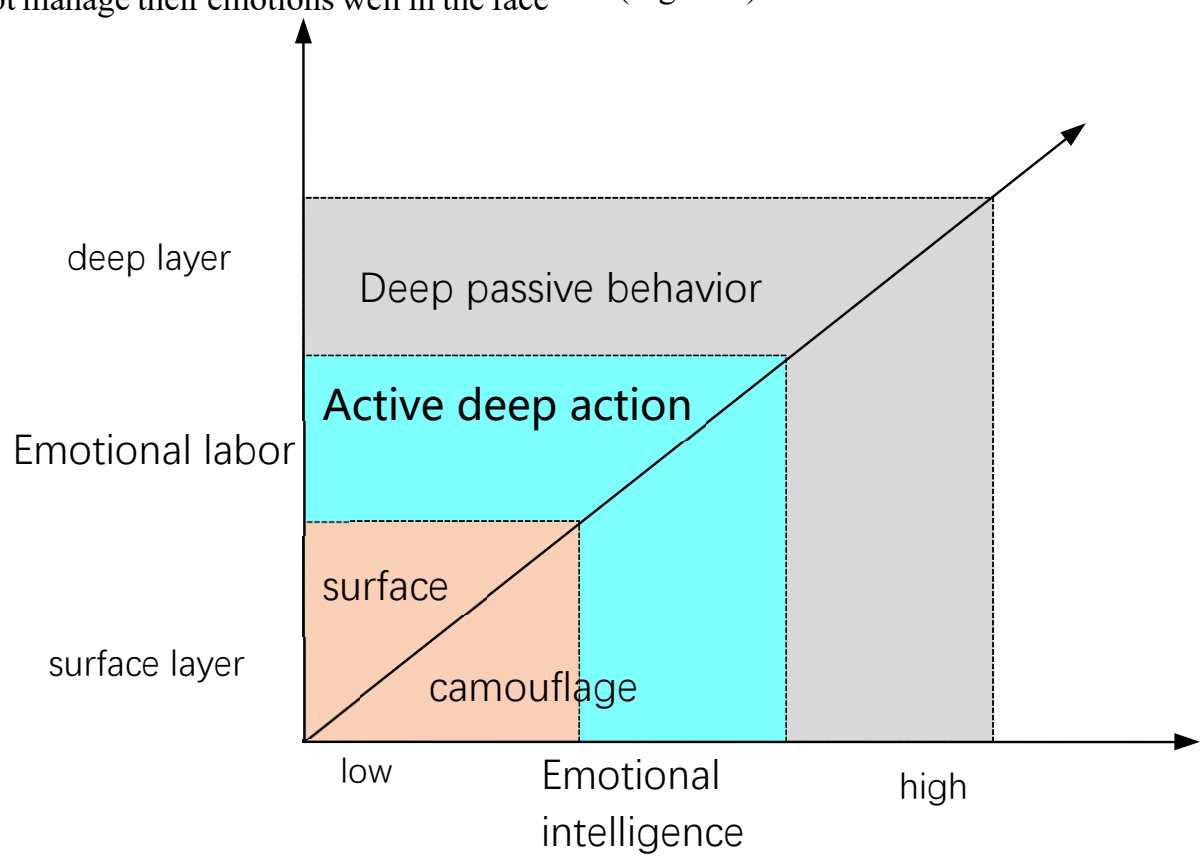

Fig1. two dimensional model of emotional intelligence and emotional labor

First layer: surface camouflage. The first layer of College Teachers' emotional labor model is surface camouflage. At this level, teachers mainly show that their emotional intelligence is low, and they seldom use emotional labor strategies in the process of work. They often use surface acting to carry out emotional labor. Under the surface camouflage state, the emotional labor of university teachers is not consistent with the original emotional state. Teachers can achieve the required emotional state of teaching work by changing their external emotions. Although this surface camouflage can enable teachers to achieve their goals in a short time, but in the long run, it is easy to cause emotional exhaustion of teachers, reduce teachers' enthusiasm for work, and then appear on the job Job burnout. Therefore, the more superficial camouflage behavior of university teachers, the higher the level of teachers' job burnout.

The second level: active deep behavior. Deep behavior can be divided into active deep behavior and passive deep behavior. Active deep behavior refers to the emotional state of college teachers to meet the work requirements by changing external and internal feelings. Under the influence of active deep behavior, there may be two results. One is that the active deep-seated behavior of teachers is positive, and the emotional intelligence of individual teachers is at a high level through their own regulation Gradually adapted to the emotional requirements of the outside world, and then transformed into passive deep behavior stage. The other is emotional exhaustion under the influence of long-term active and deep-seated behaviors. The main reason is that teachers' inner emotions are not consistent with the emotional state required by their work. Teachers need to make changes to adapt to the requirements, and these changes increase the psychological pressure and burden of teachers.

The third level: passive deep behavior. Passive deep behavior means that the teacher's emotion is consistent with the emotional state of the job requirements. In such a case, the teacher does not need to make changes. At this time, the teacher's mood and working state are also the best. A good working state will not produce job burnout, but will enhance the sense of professional identity and 
professional happiness. Passive deep behavior is a kind of real emotion. For college teachers, it is the best working condition to achieve passive deep behavior, which is also very beneficial to their physical and mental health.

\subsection{Analysis on the influencing factors and result effect of emotional labor of College Teachers}

From the perspective of influencing factors, there are many influencing factors of College Teachers' emotional labor, which can be analyzed in terms of internal factors and external factors. Internal factors include teachers' individual characteristics (gender, age, teaching experience, education background, etc.) and emotional expression rules perception factors, which are also the direct embodiment of individual emotional intelligence. According to the theory of conservation of resources, when teachers consume more psychological energy in their work, they will cause a certain loss of resources, and then there will be physical discomfort, negative emotions and other phenomena. However, due to the different characteristics and emotional expression rules of individuals, the psychological and physical reactions of individuals will also be different. The external factors mainly include social environment, school environment, team mood, family environment and so on. In fact, the emotional labor behavior of college teachers is closely related to organizational factors. For example, the emotional labor of college teachers is affected not only by individual factors, but also by organizational factors and team emotional labor level. Team emotional interaction and coordination and team feeling sharing will promote the increase of individual deep acting behavior.

From the perspective of result effect, different emotional labor strategies adopted by college teachers have different results. We can summarize them into three working states: Occupation burnout, Occupation identity and Occupation happiness, as shown in Figure 2.

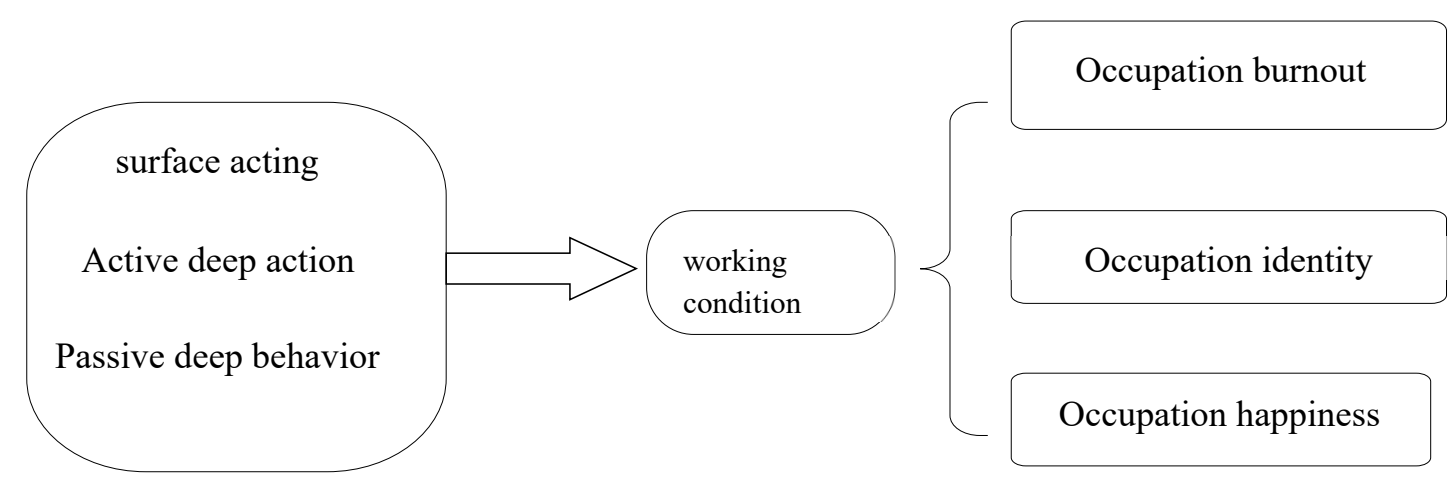

Fig2. work state under the influence of different emotional labor strategies

As mentioned above, both surface camouflage and active deep-seated behavior can cause job burnout. Emotional labor strategy is an output function, while individual emotional perception belongs to the input function. When the two are inconsistent, teachers will have discomfort. At this time, teachers should adopt appropriate emotional labor strategies to eliminate the discomfort. Professional identity means that teachers hold a positive attitude towards the profession of college teachers. This positive attitude helps to reduce the loss of resources, and the possibility of depersonalization is small, so they will be more active in teaching. However, there will be another situation. Although teachers have a strong sense of professional identity, they feel the gap between ideal and reality in the face of complicated student work and daily affairs in the work process. This kind of disappointment will also consume a lot of emotional resources, which in turn will lead to the decrease of Teachers' professional identity. Professional well-being is a kind of working state which is beneficial to the physical and mental health of university teachers. This kind of working state stems from the fact that teachers can adopt active deep behavior or passive deep behavior. On the one hand, teachers are willing to express the emotions expected by the school, and at the same time, they will actively adjust their own ideas. In this process, teachers' empathy ability and emotional intelligence have been improved, and their work happiness Feeling is enhanced.

\section{COLLEGE TEACHERS' EMOTIONAL LABOR STRATEGY MODEL BASED ON EMOTIONAL INTELLIGECE THEORY AND ITS APPLICATION}

Based on the theory of emotional intelligence, the model of College Teachers' emotional labor strategy should be constructed to improve the individual's emotional intelligence and formulate appropriate emotional labor strategy. Considering the particularity of College Teachers' profession and the requirements of university work on Teachers' competence, this paper designs emotional labor strategies from five dimensions of selfawareness, self-regulation, self motivation, empathy and social skills based on the competency model of emotional intelligence. The strategy model is shown in Figure 3. 


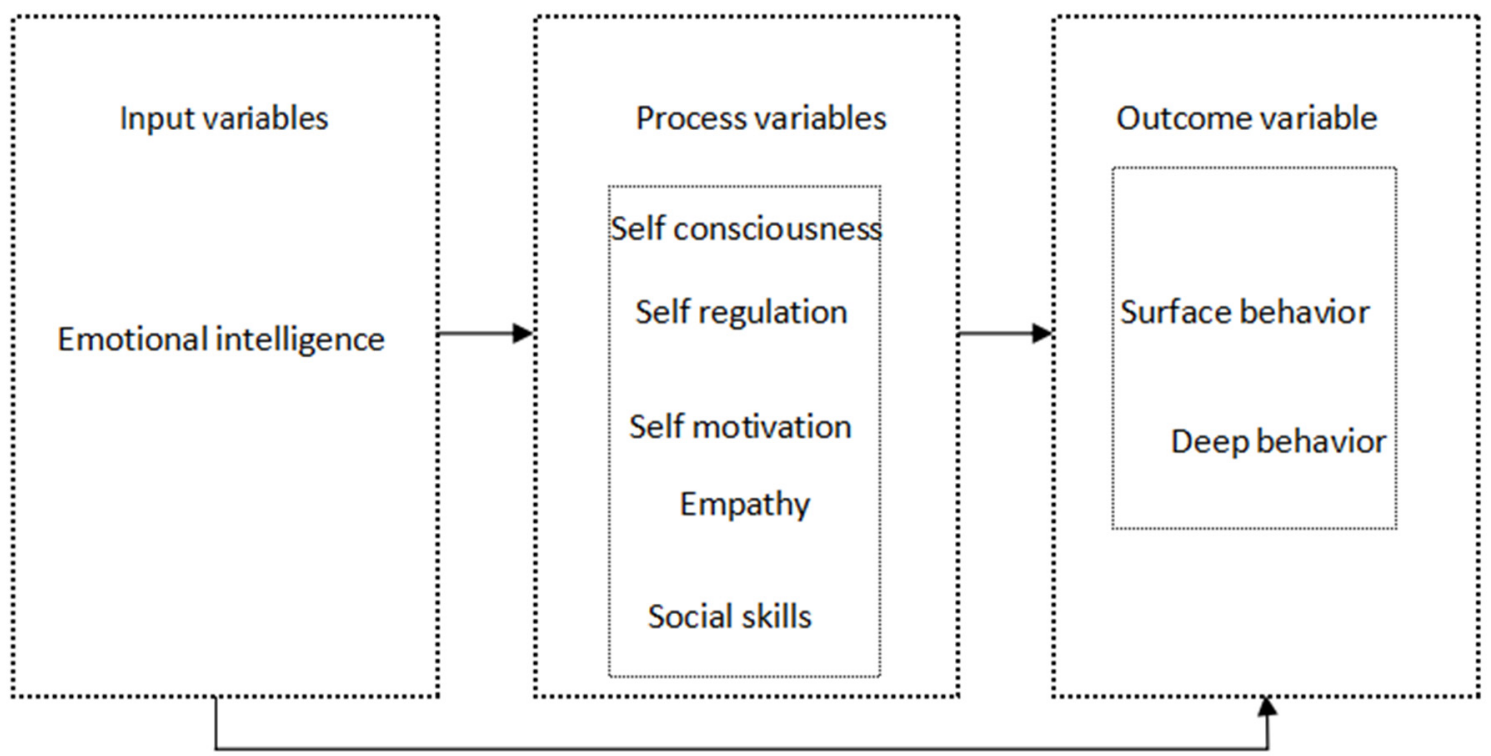

Fig3. the model of College Teachers' emotional labor strategy based on emotional intelligence theory

In the five basic dimensions of emotional intelligence, self-awareness refers to the ability to recognize and understand one's mood, emotions and emotions; selfregulation refers to the management of one's own emotions; self motivation refers to the ability to transcend material work enthusiasm, radiate energy and persistence in pursuit of goals; empathy refers to the ability to understand the emotional characteristics of others and be able to react according to others' emotions To deal with problems, social skills refer to the ability to properly handle relationships, build networks of relationships, and establish friendly relationships in a general environment.

\subsection{Self awareness strategy}

Self awareness strategy refers to the ability of insight and understanding that teachers should possess, and be able to carry out self observation and scientific self-evaluation ${ }^{[4]}$. Teachers' self insight includes the perception of their own participation in work, the awareness of thinking, etc., and a clear understanding of their own interests, hobbies, advantages and career planning. Whether a teacher's selfconsciousness is strong or not, and whether his insight and evaluation of himself is correct or not is related to the degree of his effort. Generally speaking, teachers' evaluation of himself is higher, and the degree of his efforts is also higher. On the contrary, if the self-evaluation is low, the degree of self-determination will also decrease.

Teaching work is an important content of university teachers. In the teaching process, the main interaction object of teachers is students. Under the guidance of the new curriculum concept, college teachers should establish a student-centered role cognition. To achieve this goal, teachers should actively set up and activate the classroom atmosphere, constantly innovate teaching methods, and establish trust relationship with students through many subtle ways. As different students have different attitudes towards learning, students' evaluation of teachers will be inconsistent. Therefore, teachers should not only consider the rational side of students, but also accept their emotional side in the teaching process. At this time, it is necessary for teachers to establish a certain degree of selfconfidence, which is mainly reflected in Teachers' affirmation of their own ability and the courage to actively practice their goals. College teachers should not only maintain their own professional image, but also learn to get along with students equally and narrow the psychological distance between teachers and students, which is also a key element to improve the effectiveness of teaching.

The self-awareness strategy is helpful to alleviate teachers' job burnout. When college teachers enter colleges and universities, they generally have great ambition and strong sense of achievement. However, they gradually feel the gap between ideal and reality in the busy teaching, scientific research and daily affairs, or they are unable to do their best in the teaching process. This kind of emotion has a direct impact on the professional mentality and behavior of teachers. At this time, teachers should adopt positive emotional labor strategy, strengthen self-awareness, further analyze their own advantages, and redefine development goals to enhance their sense of professional achievement. In this sense, to establish a correct self-awareness is to clarify their own advantages and disadvantages, and to formulate scientific development goals, so as to narrow the gap between their own emotions and the emotions required by the outside world, and maintain the inner balance.

\subsection{Self awareness strategy}

Self regulation strategies are mainly embodied in selfcontrol and self emotion management, which can effectively control destructive emotions. In the process of interaction with students, what teachers should do is to communicate and interact with students happily with an equal attitude. Teachers should be calm. Even in the face of students with destructive emotions, teachers should be 
able to adjust and control these emotional problems. In recent years, the enrollment scale of colleges and universities is still expanding, and the reform of teaching management system is constantly advancing, which puts forward higher requirements for College Teachers' teaching, scientific research and professional improvement. At the same time, college teachers are also faced with various life problems such as family and marriage, housing, pension, etc. under the influence of multiple pressures, some teachers are prone to negative emotions such as tension and anxiety If the mood can not be adjusted in time, it will also affect the work of teachers, and it is not conducive to their own mental health and physical health. Therefore, college teachers should master some emotional management methods. Teachers should eliminate negative emotions by changing their own cognition. Of course, this is not only at the surface level, but also on the basis of full understanding of emotions, record the individual's bad emotions, such as the time, place, events, etc., on this basis, further explore the reasons for the formation of negative emotions, or timely seek help from the outside, colleagues, family, etc Communicate and express your inner feelings. Only when teachers understand their own real emotions, as well as the harm and confusion of negative emotions, and then consciously replace them with reasonable cognition, can teachers continuously improve their ability to respond to irrational emotions and achieve effective emotional regulation.

\subsection{Self motivation strategy}

According to psychological research, motivation is the behavior that promotes people to achieve their expected goals. University Teachers belong to the group of knowledge-based employees, and their psychological needs are more hidden and diversified. In view of the particularity of College Teachers' profession, it is difficult to quantify the work effect, so it is difficult to achieve the expected effect through external incentive. Teachers use positive emotional labor strategy, that is, they should constantly carry out self motivation. The application of self motivation strategy can be carried out from the following aspects:

First of all, teachers' self emotion arouses. On the basis of full self cognition and self-evaluation, teachers can wake up the correct self emotion, which is manifested in the readjustment of development goals to match the current situation of work and enhance the individual's sense of professional identity, achievement and belonging. Secondly, teachers' independent work. Autonomous work is an important means to stimulate individual's inner potential and keep his working enthusiasm. Autonomous work is based on Teachers' self cognition and self-consciousness. Teachers often produce many positive emotions when they work on their own, which helps to resist the negative emotions in their work. In the specific practice, teachers should be able to create good conditions for their own work, such as creating a good working environment and interpersonal relationship environment, work hard according to the established goals, complete the work tasks with full emotional state, and have the awareness of lifelong learning, so as to promote the continuous improvement of their quality and ability in all aspects. Thirdly, teachers' career planning. Career planning refers to the combination of their own personality characteristics and potential resources to carry out scientific positioning of their own development ${ }^{[5]}$. There is an inseparable relationship between self motivation and career planning. Different teachers have different career development goals. For example, some teachers have strong scientific research ability, some teachers have strong teaching ability, and some teachers have certain strategic vision and can be candidates for high-level leadership. Therefore, in order to make different career plans for different types of teachers, only appropriate In order to give full play to the role of motivation, it is the same from the perspective of teachers themselves.

\subsection{Empathy strategy}

Educational communication is a purposeful process of activities. Teachers and students should constantly coordinate and communicate until a consensus is reached. Positive emotions help to enhance individual sensitivity, stimulate imagination and improve learning efficiency. Teachers should convey more positive emotions to students in teaching. Empathy is a basic requirement for the professionalization of university teachers. First of all, college teachers should master certain empathy knowledge and technology, and transform it into a special ability in teaching practice. The premise of empathy is that teachers should have certain selfcontrol ability, at the same time, teachers should also be "understanding", that is to understand students' feelings and emotions at the first time, and then feedback their understanding to students, so as to realize effective communication between teachers and students. Students need to be understood, and understanding is the premise of persuasion. Flexible use of empathy strategy can help to improve the relationship between teachers and students, and help to avoid students' negative emotions. Previous studies have shown that teachers spend more time in understanding negative emotions than in understanding positive emotions ${ }^{[6]}$ Teachers' understanding and recognition of students can also stimulate students' positive emotions. For teachers themselves, appropriate use of empathy strategy can eliminate the inconsistency between their own emotions and external emotional requirements, understand the emotional requirements of school work with the help of empathy, and then reduce the resistance and negative emotions. In such a state, teachers' professional identity will be strengthened, and then show a passive deep acting behavior, which is also teaching A manifestation of teacher's emotional intelligence improvement.

\subsection{Social skills strategy}

College teachers are in a relatively independent and closed environment, and the scope of interpersonal communication is relatively small. In daily teaching work, they are often "fighting alone". In the long run, the loneliness of teachers will be enhanced, and the skills and methods of interpersonal communication will be lack. In terms of emotion, it shows as follows: low desire for interpersonal communication, lack of enthusiasm for dealing with others, too conceited or overestimated, not considering the feelings of others, and lack of social skills and interpersonal skills will not only bring bad emotional experience to others, but also increase their own emotional distress. Positive social skills strategy is 
adopted to establish interpersonal support system and good psychological support system.

Establish interpersonal support system. The establishment of teachers' professional identity and sense of belonging mainly comes from the support and help of leaders, colleagues, students, etc. teachers' social skills strategies are not only reflected in their own active integration and selfregulation, but also reflected in the external support for teachers' interpersonal system. For example, colleges and universities should establish a platform for young teachers to exchange and communicate with each other, help teachers expand their interpersonal relationship, enhance the interaction and understanding between teachers, and give full play to students' interpersonal support for teachers. We should pay attention to the affirmation of the effectiveness of teachers' work and create a democratic and free environment for teachers' professional development.

Establish psychological support system. College teachers are faced with the pressure of professional title, scientific research, interpersonal communication and other aspects. Negative life events will increase the psychological burden of teachers. Therefore, the school should establish a special emotional care group for teachers to help teachers understand the ways and methods of emotional regulation, and provide an outlet for teachers to express their negative emotions, and professional psychological teachers should provide emotional management services for teachers. In addition to case counseling, we can also carry out team psychological counseling activities, and integrate free discussion and roleplaying training methods to help teachers sense emotions and be masters of emotions, so as to reduce the impact of negative emotions on daily work and life.

\section{ENLIGHTENMENT OF COLLEGE TEACHERS' EMOTIONAL LABOR STRATEGY MODEL BASED ON EMOTIONAL INTELLIGECE THEORY}

Based on the model of College Teachers' emotional labor strategy, in order to promote college teachers to participate in work in a more positive state, it is necessary not only for teachers' self-regulation and self guidance, but also for colleges and universities to provide necessary support for teachers' emotional labor. Specific measures can be taken from the individual level and organizational level.

\subsection{On the individual level to enhance the emotional management ability of University Teachers}

The emotional management ability of university teachers directly affects their effectiveness in adopting emotional labor strategies. From the individual level, teachers should first master certain emotional rules, deeply understand the teaching content of college teachers, understand the psychological state and behavior of students, and make adequate psychological preparation. When they encounter external pressure or negative events, teachers should have a good command of emotional rules It can moderately express emotions and reduce negative effects. Secondly, teachers should strengthen their sense of identity to their own roles and their sense of belonging to the profession of college teachers. Taking young teachers as an example, they need to face many challenges at the beginning of their work. Therefore, they need to have flexible emotional regulation ability and play the mediating role of role identification in emotional regulation. Only when we have a deep understanding and acceptance of our own work and role can we better carry out emotional labor and flexibly use emotional labor strategies.

\subsection{On the organizational level: constructing a perfect incentive mechanism for University Teachers}

The theory of two factor motivation enlightens us that organizational motivation should be designed from two aspects of health care and incentive factors. Appropriate external incentive measures can help to enhance the individual's sense of identity with the organization and enhance the individual's enthusiasm to participate in the work. Therefore, colleges and universities should play an active role in guiding and Motivating Teachers' emotional labor. On the one hand, we should provide teachers with sufficient material conditions, safe and comfortable working environment and other health care incentives. On the other hand, we should take positive incentive measures for teachers' work achievements and career development to enhance their enthusiasm for participating in work. Combined with the current situation of the incentive mechanism of university teachers in China, it is suggested to improve from the following aspects: first, improve the salary system. We should pay close attention to the relationship between salary and assessment of university teachers, optimize the existing performance evaluation indicators of university teachers, pay attention to the achievements of teaching work, enhance teachers' sense of fairness and teaching responsibility, and avoid the phenomenon of seniority. Secondly, it should pay attention to the vertical assessment of teachers, aiming at promoting the individual growth of teachers, providing them with necessary career development planning guidance and targeted training, so as to enhance teachers' sense of self gain and satisfaction. Thirdly, we should pay attention to the construction of professional teachers' team in Colleges and universities, and gather the teachers who are full of innovation and similar interests, and form different professional groups and research teams, so as to promote individual development with the strength of the team, and at the same time, it can also play the role of the team in helping and supporting the individual teachers and relieve the negative emotions encountered by teachers in their work. Fourthly, we should pay attention to teachers' emotional life and family life, provide necessary care and emotional support for teachers when they encounter difficulties in family life or confusion in emotional life, or help them solve difficulties in life, help teachers master scientific emotional management methods, and create more learning and growth opportunities for teachers.

\section{CONCLUSION}

College teachers should not only pay physical and mental 
work, but also pay a lot of emotional labor. College Teachers' emotional work is affected by many factors, among which emotional intelligence is one of the important factors. The theory of emotional intelligence mainly studies the role of emotion and emotion in intelligence activities, that is, people's ability to deal with emotional problems. Previous studies have shown that people's emotional intelligence can be transformed into emotional labor behavior, and the two have a correlation between surface behavior and deep behavior. Under the guidance of emotional intelligence theory, the construction of College emotional labor strategy model is helpful to help college teachers measure and analyze their own emotional labor status, thus promoting their physical and mental health and improving their work performance. Therefore, based on the five basic elements of individual emotional intelligence model, the necessary selfawareness strategy, self-regulation strategy, self motivation strategy, empathy strategy and social skills strategy are adopted to improve the level of individual emotional intelligence and enhance teachers' professional identity and career happiness.

\section{ACKNOWLEDGMENT}

This analysis was supported by colleagues and students in School of Economics\&Management, Nanjing Tech University. Thanks them for their hard working.

\section{REFERENCES}

1. Chen Meng, Che Hongsheng, Wang Lina, et al. Integration of emotional intelligence theory: challenge, basis and method [J]. Journal of Beijing Normal University (SOCIAL SCIENCE EDITION), 2012 (3): 14-22.

2. Brotheridge $\mathrm{C} M$, Lee $\mathrm{R}$ T. Testing a conservation of resources $\mathrm{m}$ odel of the dynam ics of em otional labor[J]. Journal of Occupational Health Psychology, 2002, 7(1):57-67.

3. Han Hongzheng, Zhang Xichao. Localization revision of College Teachers' emotional labor strategy scale [J]. Journal of China University of mining and Technology (SOCIAL SCIENCE EDITION), 2013, 15 (3): 84-89.

4. Gao Yuanyuan, Cheng Shuyuan, Zhang Guozeng. Screening of teaching self-evaluation indicators of university teachers $[\mathrm{J}]$. Education and teaching forum, 2018 (12): 15-16.

5. Peng Yongxin. Status quo and Enlightenment of career education resources development [J]. Education research and experiment, 2018, 184 (05): 94-98.

6. Yin Jie, Liu Peiduo, Yang Bo. The effect of emotional stimulation on prospective memory [J]. Psychological exploration, 2018 (2): 117-122.

7. Lin Hongying. Research on incentive mechanism of young college teachers from the perspective of emotional labor $[\mathrm{J}]$. Teaching and educating (Higher
Education Forum). 2017 (21): 54-55.

8. Liu Jiakun, Yang Heqing, Wanli. Can the emotional labor of young college teachers lead to overwork? ,The test of mediating and moderating variables [J]. Journal of China Institute of labor relations, 2020 (03): 42-50.

9. Wang Hui. Content mechanism and strategy of College Teachers' emotional labor [J]. Knowledge base, 2018 (24): 177-178.

10. Xia Wei, Wang Jing. Research on management strategy of College Teachers' emotional labor based on psychological contract [J]. Management observation, 2017 (15): 142-144. 